\title{
Diagnostic accuracy of optical coherence tomography in bladder cancer patients: A systematic review and meta-analysis
}

\author{
JUAN HUANG ${ }^{1,2^{*}}$, XUELEI MA ${ }^{1 *}$, LEI ZHANG ${ }^{3 *}$, HONGYUAN JIA $^{1}$ and FENG WANG ${ }^{1}$ \\ ${ }^{1}$ Department of Medical Oncology, Cancer Center, State Key Laboratory of Biotherapy, West China Hospital, \\ West China Medical School, Sichuan University; ${ }^{2}$ Department of Hematology, Sichuan Academy of Medical Sciences \\ and Sichuan Provincial People's Hospital; ${ }^{3}$ Department of Obstetrics and Gynecology, Chengdu Integrated \\ TCM and Western Medical Hospital, Chengdu, Sichuan 610041, P.R. China
}

Received June 24, 2017; Accepted September 28, 2017

DOI: $10.3892 / \mathrm{mco} .2018 .1566$

\begin{abstract}
A meta-analysis was performed to evaluate the accuracy of optical coherence tomography (OCT) for diagnostic accuracy studies in bladder cancer patients. English language studies reporting the diagnostic accuracy of OCT for bladder cancer were retrieved from the PubMed, EMBASE and Cochrane Library databases in December 2014. Histopathology was a reference standard. Sensitivities, specificities, positive likelihood ratios and negative likelihood ratios were calculated, and summary receiver operating characteristic curves were drawn to determine the diagnostic accuracy of OCT. Finally, 9 eligible studies (468 patients) were included in our meta-analysis. The pooled sensitivity, specificity, positive likelihood ratio and negative likelihood ratio of OCT were 0.96 [95\% confidence interval (CI): 0.94-0.98], 0.82 (95\% CI: 0.80-0.85), 6.83 (95\% CI: 3.24-14.1) and 0.05 (95\% CI: 0.02-0.16), respectively. The summary diagnostic odds ratio was 138.88 (95\% CI: 29.63-650.89) and the overall area under the curve was 0.9735 . These results suggest that OCT has excellent diagnostic performance in patients with bladder cancer and recurrent lesions.
\end{abstract}

\section{Introduction}

Bladder cancer is the most common urothelial carcinoma, with its incidence being fourth in men and tenth in women among all cancers. Despite recent advances in this field, the death rate remains relatively high. Even $70 \%$ of superficial

Correspondence to: Dr Xuelei Ma, Department of Medical Oncology, Cancer Center, State Key Laboratory of Biotherapy, West China Hospital, West China Medical School, Sichuan University, 37 Guoxuexiang Street, Chengdu, Sichuan 610041, P.R. China

E-mail: MXLei028@126.com; drmaxuelei@gmail.com

\section{${ }^{*}$ Contributed equally}

Key words: bladder cancer, optical coherence tomography, meta-analysis, diagnostic accuracy bladder tumors have a propensity for recurrence or progression within 5 years $(1,2)$. However, patients with bladder cancer are curable if diagnosed and treated early. Thus, a major concern for patients with bladder cancer is whether earlier detection is possible. However, early diagnosis of bladder cancer remains a clinical challenge (3). Currently, the reference standard of diagnosis and detection of bladder tumors is histopathology, but it is an invasive and relatively costly technique, and, occasionally, inconclusive, while conventional imaging tests, such as ultrasonography, computed tomography (CT) and magnetic resonance imaging (MRI) have significant limitations in determining the stage of bladder cancer, particularly for superficial lesions (4). Thus, a real-time, improved tool is urgently required for detecting early bladder cancer patients.

Optical coherence tomography (OCT) is a type of biomedical optical imaging technique and optical biopsy that was first introduced in 1991 (5). Unlike conventional histopathology, OCT may function as 'optical biopsy' and is analogous to ultrasound providing real-time and cross-sectional images of tissue structure at a resolution of $\sim 10 \mu \mathrm{m}$, which is similar to that of histopathology (6). OCT was initially applied for quantitative assessment of retinal structures in patients with macular edema (7). Subsequently, this approach was used in a wide spectrum of clinical applications, including human coronary arteries, structure of the digestive system, cervical epithelium and urinary tissues $(6,8-10)$. These studies considered OCT to be a successful optical imaging modality (11). Recent studies suggest that OCT is used to help diagnose bladder cancer or to detect recurrence in patients who have already been treated, and this approach may be helpful with staging and grading of bladder cancer $(12,13)$. The present meta-analysis was performed to assess the diagnostic performance of OCT in patients with bladder cancer and recurrent lesions using histopathology as the golden standard.

\section{Data collection methods}

Search strategy and selection criteria. The PubMed,EMBASE and Cochrane Library databases were searched for studies using OCT in patients with bladder cancer between January 1991 and December 2014. The searches were performed using the terms 'optical coherence tomography', 'OCT', 'optical 
biopsy', 'bladder cancer', 'transitional cell carcinoma' and 'urothelial carcinoma'. Studies were included if they compared OCT with the gold standard (histopathology/cytology) in the diagnosis of patients with bladder cancer, and reported data such as sensitivity, specificity, negative predictive value (NPV), positive predictive value (PPV), true-positive (TP), false-positive (FP), true-negative (TN) and false-negative (FN). Studies were excluded if they were reviews, laboratory articles or case reports, if they were not published in English, if there was duplication of data, or if they did not provide detailed data to perform a meta-analysis.

Study selection and data extraction. The eligible studies were assessed by two independent reviewers (J Huang and XL Ma). Disagreements on study selection or data extraction were resolved by consensus or by discussion with a third reviewer (L Liu). The data were extracted from eligible studies using a standardized data collection form, including related items: First author, publication year, number of patients, patient source, study design, patient age, reference standard for the diagnosis and other useful information. TP, FP, TN and FN were eventually acquired/calculated to perform the meta-analysis.

Quality assessment. Quality assessment was independently performed by two investigators (J Huang and XL Ma) using the Quality Assessment Tool for Diagnostic Accuracy Studies (QUADAS) (14). Briefly, this tool assesses diagnostic trials and contains 14 questions. Each item was assessed as 'yes', 'no' or 'unclear'. Any discrepancies were resolved by consensus.

Data analysis/statistical analysis. The present meta-analysis was performed to assess the accuracy of OCT in patients with bladder cancer. The pooled estimates were determined by the fixed-effects model (Mantel-Haenszel method) if significant heterogeneity was not detected, whereas the random-effects model (DerSimonian-Laird method) was applied if there was heterogeneity between studies. The $\chi^{2}$ test and $\mathrm{I}^{2}$ statistic were applied to assess heterogeneity: $\mathrm{P}<0.05$ for the $\chi^{2}$ test and $\mathrm{I}^{2}>50 \%$ were considered to indicate heterogeneity between studies. The summary Receiver Operating Characteristic (sROC) approach was a type of standard method applied in the evaluation of diagnostic technologies of diagnostic accuracy studies reporting pairs of sensitivity and specificity. The Q-point is the point on the sROC curve where sensitivity equals specificity (15). The area under the curve (AUC) was applied to assess the quality of the diagnostic tool, which is defined as perfect when the AUC is $100 \%$ (16). The data including TP, FP, TN, FN were acquired using RevMan 5.1 software (Cochrane Collaboration, Oxford, UK). The pooled estimates [sensitivity, specificity, positive likelihood ratio (LR), negative LR and diagnostic odd ratio (OR)] were calculated using Meta-Disc software, version 1.4 (Unit of Clinical Biostatistics, Ramon y Cajal Hospital, Madrid, Spain).

Assessment of publication bias. Begg's test and funnel plots were used to determine potential publication bias using STATA 11.0 software (STATA Corporation, College Station, TX, USA), and $\mathrm{P}>0.05$ was not considered as potential publication bias.

\section{Results}

Eligible studies. The electronic search through PubMed, EMBASE and the Cochrane Library identified 73 publications. After screening the titles and abstracts, 45 studies were considered for further evaluation. Of the 45 studies, only 9 met the inclusion criteria and were considered suitable for inclusion in the meta-analysis for OCT and bladder cancer (Fig. 1) (4,17-24). All the eligible studies were published between 2002 and 2014. A total of 468 patients were included in these studies (range, 20-105 patients). The clinical characteristics of the patients and other useful information, such as authors, country and tumor stage, are summarized in Table I.

Quality assessment. Quality assessment was performed in all the included studies using the QUADAS tool (Table II). Of the 14 items, at least 10 items were clearly stated in each eligible study, which indicates high quality.

Diagnostic accuracy of OCT in bladder cancer. The forest plot of sensitivity and specificity for diagnostic accuracy of OCT in bladder cancer patients is presented in Fig. 2. The sensitivity of the eligible studies ranged from 0.76 to 1.00 , and the specificity ranged from 0.62 to 0.97 . The pooled sensitivity and specificity with $95 \%$ confidence interval (95\% CI) for OCT were 0.96 (95\% CI: 0.94-0.98) and 0.82 (95\% CI: 0.80-0.85), respectively. The pooled PLRs and NLRs were 6.83 (95\% CI: 3.24-14.1) and 0.05 (95\% CI: 0.02-0.16), respectively. The combined diagnostic odds ratio (DOR) in the diagnosis of bladder cancer was 138.88 (95\% CI: 29.63-650.89). The pooled values (sensitivity, specificity, PLR, NLR and DOR) are listed in Table III. The sROC and the $\mathrm{Q}^{*}$ index were used to assess diagnostic accuracy. The AUC and the $\mathrm{Q}^{*}$ index were 0.9735 and 0.9257 , respectively.

Study heterogeneity and publication bias. Heterogeneity was assessed on the basis of the $\chi^{2}$ test and the $\mathrm{I}^{2}$ statistic. There was statistically significant heterogeneity in sensitivity $\left(\chi^{2}=26.12, \mathrm{P}=0.0010 ; \mathrm{I}^{2}=69.4 \%\right)$, specificity $\left(\chi^{2}=109.09\right.$, $\left.\mathrm{P}=0.0000 ; \mathrm{I}^{2}=92.7 \%\right)$, positive LR $\left(\chi^{2}=154.93, \mathrm{P}=0.0000\right.$; $\left.\mathrm{I}^{2}=94.8 \%\right)$, negative LR $\left(\chi^{2}=35.40, \mathrm{P}=0.0000 ; \mathrm{I}^{2}=77.4 \%\right)$ and DOR $\left(\chi^{2}=49.94, \mathrm{P}=0.0000 ; \mathrm{I}^{2}=84.0 \%\right)$. Publication bias was analyzed by Begg's test and funnel plots. No significant publication bias was found for DOR in the present meta-analysis $(\mathrm{P}=0.83)$

\section{Discussion}

Bladder cancer is the sixth most common type of cancer worldwide. Approximately $75-85 \%$ of patients have superficial bladder cancer when first diagnosed, confined to the mucosa or lamina propria. However, a significant proportion of patients with superficial bladder cancer are at risk for recurrence and progression. The risk factors for tumor recurrence and/or progression may be summarized as follows: i) New tumor occurrence and progression; ii) tumor implantation during transurethral resection (TUR); iii) residual tumor following incomplete resection and/or iv) overlooking of neoplastic lesions such as dysplasia and carcinoma in situ (CIS) (25). Tumor recurrence and/or progression are partially attributed 


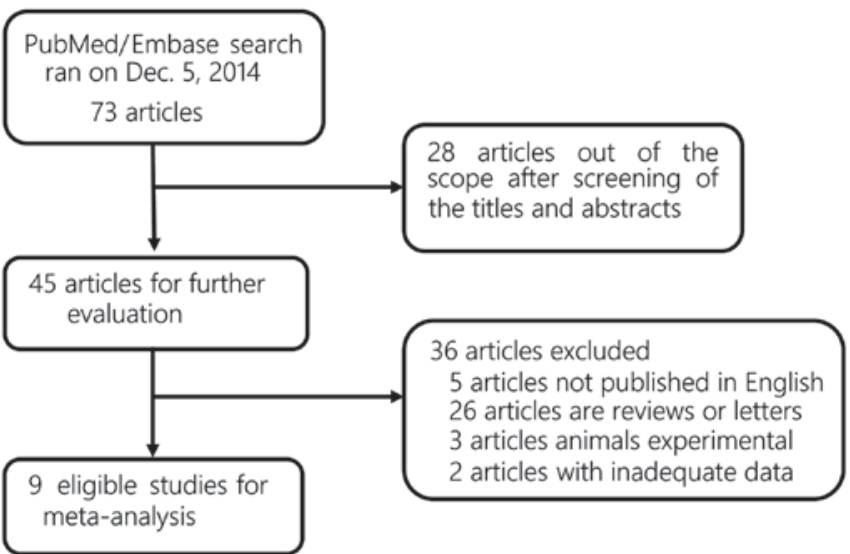

Figure 1. Flow diagram of the study selection process.

to the detection tools. Therefore, new diagnostic modalities for detection and monitoring are required to decrease the rate of tumor recurrence and/or progression, which affect the patient outcome.

Accumulated evidence indicates that current methods of diagnosing bladder cancer mainly rely on histological and cytological examination of tissue. White-light cystoscopy in combination with TUR are currently applied to resect lesions, followed by histopathological examination to evaluate the level of bladder wall involvement. Histopathological examination is currently the gold standard for identifying bladder cancer tissue. This pathological examination is a time-consuming procedure that requires removal of suspicious lesions, followed by fixing and staining prior to diagnosis. Furthermore, histopathological evaluation in the diagnosis of bladder cancer has certain limitations in terms of real-time differentiation of grade and stage of superficial bladder cancer, since relevant early-stage and precancerous lesions are often missed (26-28). Cystoscopic evaluation is available for papillary transitional cell carcinoma (TCC); however, it is of low diagnostic sensitivity and specificity for differentiating non-papillary TCC, particularly CIS (29-31). Urine cytology has been proven to have potential advantages for bladder CIS and high-grade neoplasms, but is of quite low sensitivity for low-grade lesions and follow-up investigations of bladder cancer (32). The abovementioned methods are invasive detection techniques that remain insufficiently validated in terms of diagnosis and follow-up, particularly for low-grade bladder cancer. In addition, as regards non-invasive detection tools, due to the limited resolution, conventional imaging tools, including intravenous pyelography, CT and MRI, fail to detect early-stage bladder cancer (3). Furthermore, real-time grading of bladder cancer is clinically important, but the previously mentioned approaches for diagnosis and grading cannot provide this information. Thus, a new, real-time, promising detection method is needed to enable accurate diagnosis for superficial bladder cancer and recurrent disease.

OCT as a real-time high-resolution and non-invasive technology, may provide cross-sectional imaging of biological tissue to a depth of 1-2 mm (33). This tool may increase accuracy and specificity in differentiating grade and stage in bladder cancerous lesions in particular, offering great potential for the detection of precancerous and low-grade lesions, 
Table II. Quality assessment of included studies.

\begin{tabular}{|c|c|c|c|c|c|c|c|c|c|}
\hline \multirow[b]{2}{*}{ Item } & \multicolumn{9}{|c|}{ Studies (Refs.) } \\
\hline & $\begin{array}{c}\text { Goh and } \\
\text { Lerner } \\
\text { (12) }\end{array}$ & $\begin{array}{c}\text { Ren } \\
\text { et al (19) }\end{array}$ & $\begin{array}{l}\text { Hermes } \\
\text { et al (17) }\end{array}$ & $\begin{array}{l}\text { Manyak } \\
\text { et al (4) }\end{array}$ & $\begin{array}{l}\text { Gladkova } \\
\text { et al (22) }\end{array}$ & $\begin{array}{c}\text { Karl } \\
\text { et al (18) }\end{array}$ & $\begin{array}{l}\text { Wang } \\
\text { et al (23) }\end{array}$ & $\begin{array}{l}\text { Schmidbauer } \\
\text { et al (20) }\end{array}$ & $\begin{array}{l}\text { Lingley- } \\
\text { Papadopoulos } \\
\text { et al (24) }\end{array}$ \\
\hline 1 & $\mathrm{Y}$ & $\mathrm{N}$ & Y & $\mathrm{Y}$ & $\mathrm{N}$ & Y & $\mathrm{Y}$ & Y & $Y$ \\
\hline 2 & $\mathrm{Y}$ & $\mathrm{Y}$ & $\mathrm{Y}$ & $\mathrm{Y}$ & $\mathrm{Y}$ & $\mathrm{Y}$ & $\mathrm{Y}$ & $\mathrm{Y}$ & $\mathrm{Y}$ \\
\hline 3 & $\mathrm{Y}$ & $\mathrm{Y}$ & Y & $\mathrm{Y}$ & $\mathrm{Y}$ & $\mathrm{Y}$ & $\mathrm{Y}$ & $\mathrm{Y}$ & $\mathrm{Y}$ \\
\hline 4 & $\mathrm{Y}$ & $\mathrm{Y}$ & Y & $\mathrm{Y}$ & $\mathrm{Y}$ & $\mathrm{Y}$ & $\mathrm{Y}$ & $\mathrm{N}$ & $\mathrm{Y}$ \\
\hline 5 & $\mathrm{Y}$ & $\mathrm{Y}$ & $\mathrm{Y}$ & $\mathrm{Y}$ & $\mathrm{Y}$ & $\mathrm{Y}$ & $\mathrm{Y}$ & $\mathrm{Y}$ & $\mathrm{Y}$ \\
\hline 6 & $\mathrm{Y}$ & $\mathrm{Y}$ & $\mathrm{Y}$ & $\mathrm{Y}$ & $\mathrm{Y}$ & $\mathrm{Y}$ & $\mathrm{Y}$ & $\mathrm{Y}$ & $\mathrm{Y}$ \\
\hline 7 & $\mathrm{Y}$ & $\mathrm{Y}$ & $\mathrm{Y}$ & $\mathrm{Y}$ & $\mathrm{Y}$ & $\mathrm{Y}$ & $\mathrm{Y}$ & $\mathrm{Y}$ & $\mathrm{Y}$ \\
\hline 8 & $\mathrm{Y}$ & $\mathrm{Y}$ & $\mathrm{Y}$ & $\mathrm{Y}$ & $\mathrm{Y}$ & $\mathrm{Y}$ & $\mathrm{Y}$ & $\mathrm{Y}$ & $\mathrm{Y}$ \\
\hline 9 & $\mathrm{Y}$ & $\mathrm{Y}$ & $\mathrm{Y}$ & $\mathrm{N}$ & $\mathrm{Y}$ & $\mathrm{N}$ & $\mathrm{N}$ & $\mathrm{Y}$ & $\mathrm{Y}$ \\
\hline 10 & $\mathrm{Y}$ & $\mathrm{Y}$ & Y & Y & Y & Y & Y & $\mathrm{Y}$ & $\mathrm{Y}$ \\
\hline 11 & $\mathrm{Y}$ & $\mathrm{Y}$ & $\mathrm{Y}$ & $\mathrm{Y}$ & $\mathrm{Y}$ & $\mathrm{Y}$ & $\mathrm{Y}$ & $\mathrm{Y}$ & $\mathrm{Y}$ \\
\hline 12 & $\mathrm{Y}$ & $\mathrm{Y}$ & $\mathrm{Y}$ & $\mathrm{Y}$ & $\mathrm{Y}$ & $\mathrm{Y}$ & $\mathrm{Y}$ & $\mathrm{Y}$ & $\mathrm{Y}$ \\
\hline 13 & $\mathrm{Y}$ & $\mathrm{U}$ & $\mathrm{Y}$ & $\mathrm{Y}$ & $\mathrm{Y}$ & $\mathrm{Y}$ & $\mathrm{Y}$ & $\mathrm{N}$ & $\mathrm{Y}$ \\
\hline 14 & $\mathrm{Y}$ & $\mathrm{U}$ & $\mathrm{Y}$ & $\mathrm{Y}$ & $\mathrm{Y}$ & $\mathrm{Y}$ & $\mathrm{U}$ & $\mathrm{N}$ & $\mathrm{Y}$ \\
\hline
\end{tabular}

QUADAS criteria

1. Was the spectrum of patients' representative of the patients who will receive the test in practice?

2. Were selection criteria clearly described?

3 . Is the reference standard likely to correctly classify the target condition?

4. Is the time period between reference standard and index test short enough to be reasonably sure that the target condition did not change between the two tests?

5. Did the whole sample or a random selection of the sample, receive verification using a reference standard or diagnosis?

6. Did patients receive the same reference standard regardless of the index test result?

7. Was the reference standard independent of the index test?

8. Was the execution of the index test described in sufficient detail to permit replication of the test?

9. Was the execution of the reference standard described in sufficient detail to permit its replication?

10. Were the index test results interpreted without knowledge of the results of the reference standard?

11. Were the reference standard results interpreted without knowledge of the results of the index test?

12. Were the same clinical data available when test results were interpreted as would be available when the test is used in practice?

13. Were uninterpretable/intermediate results reported?

14. Were withdrawals from the study explained?

Y, yes; N, no; U, unclear; QUADAS, Quality Assessment Tool for Diagnostic Accuracy Studies.

Table III. Diagnostic accuracy of OCT in bladder cancer in 9 selected studies.

\begin{tabular}{lcc}
\hline Data analysis & Pooled value & 95\% confidence interval \\
\hline Sensitivity & 0.96 & $0.94-0.98$ \\
Specificity & 0.82 & $0.80-0.85$ \\
PLR & 6.83 & $3.24-14.41$ \\
NLR & 0.05 & $0.02-0.16$ \\
DOR & 138.88 & $29.63-650.89$ \\
\hline
\end{tabular}

OCT, optical coherence tomography; DOR, diagnostic odds ratio; PLR, positive likelihood ratio; NLR, negative likelihood ratio.

and may also be available for visualization and resection. To date, OCT has been widely applied to diagnose patients suffering from bladder cancer. Hermes et al, as well as other groups, demonstrated that OCT is a clinically useful tool for bladder cancer diagnosis with high sensitivity and specificity $(13,17)$. Johnson et al demonstrated the feasibility of OCT in the diagnosis of glaucoma by a systematic review and meta-analysis (34). OCT diagnostic technologies for bladder cancer have not been compared with histopathology examination by meta-analysis to date.

To the best of our knowledge, this is the first meta-analysis investigating the diagnostic accuracy of emerging OCT in bladder cancer. Histopathology served as the reference standard. A total of 9 eligible studies (468 patients) were included in our meta-analysis, and the pooled estimated sensitivity and specificity of OCT in detecting bladder cancer were 0.96 (95\% CI: 0.94-0.98) and 0.82 (95\% CI: 0.80-0.85), respectively. As seen in Table I, the included patients were mainly low-grade and early-stage (superficial bladder cancer and CIS). The results of the present meta-analysis suggested that 


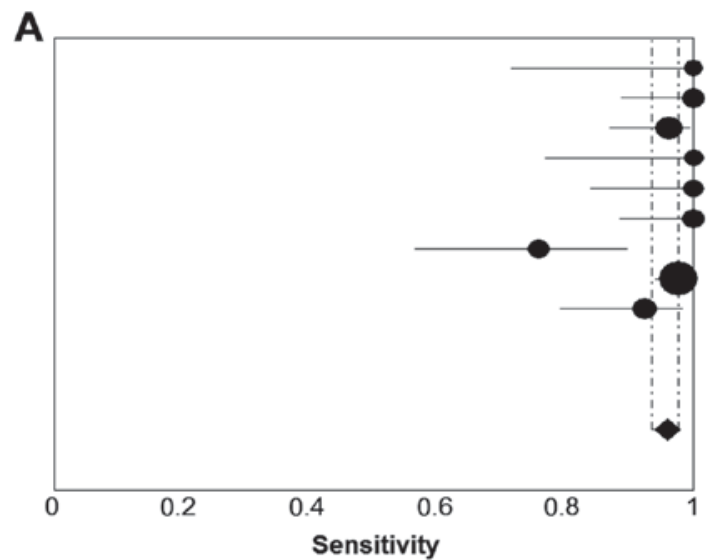

B

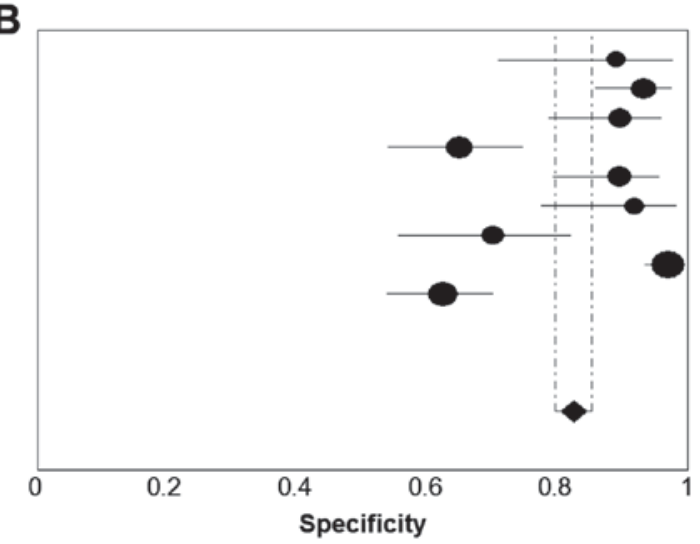

Seth P 2008

Barbara Hermes 2008

Hugang Ren 2009

a. Karl 2010

MICHAEL J 2005

ELENA V. ZAGAYNOVA 2002

Natalia Gladkova 2012

Joerg Schmidbauer 2009

Colleen A.2007
Sensitivity $(95 \% \mathrm{Cl})$

$1.00 \quad(0.72-1.00)$

$1.00 \quad(0.89-1.00)$

$0.96 \quad(0.87-1.00)$

$1.00 \quad(0.77-1.00)$

$1.00 \quad(0.84-1.00)$

$1.00 \quad(0.88-1.00)$

$0.76 \quad(0.56-0.90)$

$0.98 \quad(0.94-0.99)$

$0.92 \quad(0.79-0.98)$

Pooled Sensitivity $=0.96(0.94$ to 0.98$)$

Chi-square $=26.12 ; \mathrm{df}=8(\mathrm{p}=0.0010)$

Inconsistency (I-square) $=69.4 \%$

Figure 2. Forest plot of sensitivity and specificity of optical coherence tomography in the diagnosis of patients with bladder cancer. CI, confidence interval.

OCT has excellent diagnostic performance for low-grade and early-stage disease in bladder cancer patients.

In this study, the OCT signal was assessed per se, as well as in combination with other imaging modalities, such as fluorescence spectroscopy. The results revealed that there was no significant difference in the diagnostic value (data not shown). The factors limiting the validity of the results are summarized as follows: i) The eligible studies mainly analyzed the diagnostic role of OCT in early-stage bladder cancer patients; and ii) there was not enough evidence for further analysis.

DOR is a single indicator of diagnostic accuracy that combines the data into a number (9); it ranges from 0 to infinity, and higher values indicate higher accuracy. Although there is no absolute cut-off, a good diagnostic test must have a DOR of $>100$. The pooled DOR value for OCT was 138.88 (95\% CI: 29.63-650.89) in the present meta-analysis. AUC was also applied to determine the diagnostic accuracy. The value of AUC was $97.35 \%$ in the diagnosis of bladder cancer. Taken together, these results indicate that OCT, a real-time high-resolution and non-invasive technique, has a very high level of accuracy.

There were several limitations in our studies. The major limitation of OCT are its innate characteristics. OCT functions as an 'optical biopsy' and is equivalent to ultrasound based on depth-resolved detection of elastic light scattering. The imaging depth is usually limited to $<2 \mathrm{~mm}$ due to light scattering by the sample. Therefore, OCT has the potential to differentiate grade and stage of early bladder cancer, but is less useful for advanced tumors. Combining OCT with other imaging modalities, such as fluorescence spectroscopy or advanced analysis of the OCT signal itself, may distinguish between benign and malignant bladder tissue, regardless of disease stage. Another limitation of OCT is the difficulty in differentiating between chronic inflammatory tissue and CIS, which is also the case for edema and scar tissue. In addition, the numbers of the patients in the eligible studies were small, and the majority had low-grade (non-invasive) bladder cancer and CIS, which may have introduced a bias to the results. Therefore, a study including a larger population is required to assess the accuracy of OCT. Selective reporting biases are one of common risks with diagnostic studies. At present, the results appear to be in favor of OCT. In addition, the exclusion of studies, regardless of the reason, may have also led to potential reporting bias. It is also noteworthy that this clinical diagnostic tool has not been widely adopted and there are no consolidated guidelines regarding imaging for bladder cancer.

Significant heterogeneity was found in the present meta-analysis. The heterogeneity in sensitivity, specificity, positive LR, negative LR and DOR were $\chi^{2}=26.12, \mathrm{P}=0.0010$, $\mathrm{I}^{2}=69.4 \% ; \chi^{2}=109.09, \mathrm{P}=0.0000, \mathrm{I}^{2}=92.7 \% ; \chi^{2}=154.93$, $\mathrm{P}=0.0000, \mathrm{I}^{2}=94.8 \% ; \chi^{2}=35.40, \mathrm{P}=0.0000, \mathrm{I}^{2}=77.4 \%$; and $\chi^{2}=49.94, \mathrm{P}=0.0000, \mathrm{I}^{2}=84.0 \%$, respectively. This indicated that there were significant variations in the studies, such as the examiner's experience, analysis imaging using the OCT signal per se or combining OCT with other imaging modalities, number of patients or detected lesions and study design. In addition, Begg's test is likely underpowered due to the small number of studies and the high heterogeneity. 
The meta-analysis indicated that OCT may be a useful and promising tool for earlier detection, diagnosis and staging of superficial low-grade tumors and CIS, as well as detection of recurrent tumors. Since real-time high-resolution OCT images may be obtained in a non-invasive manner, it would play an important role in guided therapies. In particular, this tool may prove useful for guidance of biopsy procedures and staging of suspected tissue areas within the bladder. However, multicenter and prospective studies are required to provide definitive answers and evaluate the potential diagnostic accuracy of OCT in the detection of early bladder cancer.

\section{Acknowledgements}

The present study was supported by the National Natural Science Foundation of China (grant no. NSFC 81101729) and the Soft Science Project of Sichuan Province (grant no. 2010ZR0161).

\section{References}

1. Hall MC, Chang SS, Dalbagni G, Pruthi RS, Seigne JD, Skinner EC, Wolf JS Jr and Schellhammer PF: Guideline for the management of nonmuscle invasive bladder cancer (stages Ta, T1 and Tis): 2007 update. J Urol 178: 2314-2330, 2007.

2. Siegel R, Naishadham D and Jemal A: Cancer statistics, 2012. CA Cancer J Clin 62: 10-29, 2012.

3. Messing EM and Catalona W: Urothelial tumors of the urinary tract. In: Campbell's Urolology. 9th edition. WB Saunders, Philadelphia, pp2383-2411, 2002.

4. Manyak MJ, Gladkova ND, Makari JH, Schwartz AM, Zagaynova EV, Zolfaghari L, Zara JM, Iksanov R and Feldchtein FI: Evaluation of superficial bladder transitional-cell carcinoma by optical coherence tomography. J Endourol 19: 570-574, 2005.

5. Huang D, Swanson EA, Lin CP, Schuman JS, Stinson WG, Chang W, Hee MR, Flotte T, Gregory K, Puliafito CA, et al: Optical coherence tomography. Science 254: 1178-1181, 1991.

6. Tearney G, Brezinski M, Southern J, Bouma B, Boppart S and Fujimoto J: Optical biopsy in human urologic tissue using optical coherence tomography. J Urol 157: 1915-1919, 1997.

7. Hee MR, Puliafito CA, Wong C, Duker JS, Reichel E, Rutledge B, Schuman JS, Swanson EA and Fujimoto JG: Quantitative assessment of macular edema with optical coherence tomography. Arch Ophthalmol 113: 1019-1029, 1995.

8. Gogas BD, Farooq V, Onuma Y, Magro M, Radu MD, van Geuns RJ, Regar E and Serruys PW: 3-dimensional optical frequency domain imaging for the evaluation of primary percutaneous coronary intervention in ST-segment elevation myocardial infarction. Int J Cardiol 151: 103-105, 2011.

9. Sivak MV Jr, Kobayashi K, Izatt JA, Rollins AM, Ung-Runyawee R, Chak A, Wong RC, Isenberg GA and Willis J: High-resolution endoscopic imaging of the GI tract using optical coherence tomography. Gastrointest Endosc 51: 474-479, 2000.

10. Gallwas J, Turk L, Friese K and Dannecker C: Optical coherence tomography as a non-invasive imaging technique for preinvasive and invasive neoplasia of the uterine cervix. Ultrasound Obstet Gynecol 36: 624-629, 2010.

11. Carignan CS and Yagi Y: Optical endomicroscopy and the road to real-time, in vivo pathology: Present and future. Diagn Pathol 7: 98, 2012.

12. Goh AC and Lerner SP: Application of new technology in bladder cancer diagnosis and treatment. World J Urol 27: 301-307, 2009.

13. Wessels R, De Bruin DM, Faber DJ, Van Leeuwen TG, Van Beurden $\mathrm{M}$ and Ruers TJ: Optical biopsy of epithelial cancers by optical coherence tomography (OCT). Lasers Med Sci 29: $1297-1305,2014$

14. Whiting P, Rutjes AW, Reitsma JB, Bossuyt PM and Kleijnen J: The development of QUADAS: A tool for the quality assessment of studies of diagnostic accuracy included in systematic reviews. BMC Med Res Methodol 3: 25, 2003.
15. Moses LE, Shapiro D and Littenberg B: Combining independent studies of a diagnostic test into a summary roc curve: Dataanalytic approaches and some additional considerations. Stat Med 12: 1293-1316, 1993.

16. Swets JA: Measuring the accuracy of diagnostic systems. Science 240: 1285-1293, 1988.

17. Hermes B, Spöler F, Naami A, Bornemann J, Först M, Grosse J, Jakse $\mathrm{G}$ and Knüchel R: Visualization of the basement membrane zone of the bladder by optical coherence tomography: Feasibility of noninvasive evaluation of tumor invasion. Urology 72 : 677-681, 2008.

18. Karl A, Stepp H, Willmann E, Buchner A, Hocaoglu Y, Stief C and Tritschler S: Optical coherence tomography for bladder cancer-ready as a surrogate for optical biopsy?-Results of a prospective mono-centre study. Eur J Med Res 15: 131-134, 2010

19. Ren H, Waltzer WC, Bhalla R, Liu J, Yuan Z, Lee CS, Darras F, Schulsinger D, Adler HL, Kim J, et al: Diagnosis of bladder cancer with microelectromechanical systems-based cystoscopic optical coherence tomography. Urology 74: 1351-1357, 2009.

20. Schmidbauer J, Remzi M, Klatte T, Waldert M, Mauermann J, Susani M and Marberger M: Fluorescence cystoscopy with high-resolution optical coherence tomography imaging as an adjunct reduces false-positive findings in the diagnosis of urothelial carcinoma of the bladder. Eur Urol 56: 914-919, 2009.

21. Zagaynova EV, Streltsova OS, Gladkova ND, Snopova LB, Gelikonov GV, Feldchtein FI and Morozov A: In vivo optical coherence tomography feasibility for bladder disease. J Urol 167: 1492-1496, 2002

22. Gladkova N, Kiseleva E, Streltsova O, Prodanets N, Snopova L, Karabut M, Gubarkova E and Zagaynova E: Combined use of fluorescence cystoscopy and cross-polarization OCT for diagnosis of bladder cancer and correlation with immunohistochemical markers. J Biophotonics 6: 687-698, 2013.

23. Wang ZG, Lee C, Waltzer W, Yuan ZJ, Wu ZL, Xie HK and Pan YT: Optical coherence tomography for noninvasive diagnosis of epithelial cancers. Conf Proc IEEE Eng Med Biol Soc 1: 129-132, 2006.

24. Lingley-Papadopoulos CA, Loew MH, Manyak MJ and Zara JM: Computer recognition of cancer in the urinary bladder using optical coherence tomography and texture analysis. J Biomed Opt 13: 024003, 2008.

25. Zaak D and Hofstetter A: The current diagnosis of superficial bladder cancer must be reconsidered. Urol Int 69: 85-90, 2002.

26. Shariat SF, Palapattu GS, Karakiewicz PI, Rogers CG, Vazina A, Bastian PJ, Schoenberg MP, Lerner SP, Sagalowsky AI and Lotan Y: Discrepancy between clinical and pathologic stage: Impact on prognosis after radical cystectomy. Eur Urol 51: 137-151, 2007.

27. Ficarra V, Dalpiaz O, Alrabi N, Novara G, Galfano A and Artibani W: Correlation between clinical and pathological staging in a series of radical cystectomies for bladder carcinoma. BJU Int 95: 786-790, 2005.

28. Stein JP: Indications for early cystectomy: Urology 62: 591-595, 2003.

29. Leyh H, Marberger M, Conort P, Sternberg C, Pansadoro V, Pagano F, Bassi P, Boccon-Gibod L, Ravery V, Treiber U and Ishak L: Comparison of the BTA stat test with voided urine cytology and bladder wash cytology in the diagnosis and monitoring of bladder cancer. Eur Urol 35: 52-56, 1999.

30. Kriegmair M, Baumgartner R, Knüchel R, Stepp H, Hofstädter F and Hofstetter A: Detection of early bladder cancer by 5-aminolevulinic acid induced porphyrin fluorescence. J Urol 155: 105-110, 1996.

31. Cina SJ, Epstein JI, Endrizzi JM, Harmon WJ, Seay TM and Schoenberg MP: Correlation of cystoscopic impression with histologic diagnosis of biopsy specimens of the bladder. Hum Pathol 32: 630-637, 2001.

32. Cajulis RS, Haines GK III, Frias-Hidvegi D, McVary K and Bacus JW: Cytology, flow cytometry, image analysis, and interphase cytogenetics by fluorescence in situ hybridization in the diagnosis of transitional cell carcinoma in bladder washes: A comparative study. Diagn Cytopathol 13: 214-224, 1995.

33. Fujimoto JG, Pitris C, Boppart SA and Brezinski ME: Optical coherence tomography: An emerging technology for biomedical imaging and optical biopsy. Neoplasia 2: 9-25, 2000.

34. Johnson ZK, Siddiqui MA and Azuara-Blanco A: The quality of reporting of diagnostic accuracy studies of optical coherence tomography in glaucoma. Ophthalmology 114: 1607-1612, 2007. 